\title{
THE UTILITIES BUREAU
}

\section{By Felix Frankfurter,}

Law School, Harvard University.

Mr. Chairman and Gentlemen: I have been asked to elaborate the obvious. There is one factor in all this problem that we can all agree upon, and it is a vital one frequently overlooked. It is just this: that there is not an identity of interest between the utilities and the community which the utility serves. The interests are conflicting, not identical; there is, however, a need of composing or adjusting these different interests. From that follow several necessary implications. The way to compose different interests, the way to reconcile conflicting interests, is, according to the theory of Anglo-Saxon law, a balanced representation of those interests.

In order to have a balanced representation there must be full possession of the facts on each side necesssary to the decision of each case. Up to date, gentlemen, the opposing interests have not been well balanced. There is concentration of ability on one side but lack of concentration of ability on the other. Concentration of ability and intelligence on the part of the utilities, but lack of concentration of ability on the part of the community. The reason is plain. The jurisdiction of our municipalities must stop at the limits of the city line. The interests of the municipalities, however, extend beyond the city line. There must therefore be devised some machinery outside of the local structure to meet that gap between need and power. Recognizing that difficulty, Mayor Blankenburg and his associates have proposed and suggested the formation of the Utilities Bureau. The Bureau thus suggested is to serve as a way out of the difficulties in which several municipalities find themselves today. I will take a few of the many examples. The city of New York is about to attempt to secure a reduction in the telephone charges in the city of New York. The telephone company has been through that conflict in other cities, and is well equipped with the results of such litigation as to costs and valuation, while the city of New York has not those facts. In order to get them, it must spend an amount of money and time out of all proportion to the need of the situation. 
The city of Boston is recontracting its relation with the Edison Electric Company. There is a stall, there is a block, in the whole situation, because the company insists upon a price of $\$ 87.50$ per light a year, and the Mayor of Boston thinks that is fair, but several city associations and organizations insist, and Mr. Cooke, Director of Public Works of the city of Philadelphia agrees with them, that the necessary light shall be secured at a maximum of $\$ 70$ a year. Isn't it absurd to think that the Mayor of Boston should be in a conflict with the Director of Public Works of Philadelphia, as to the present-day fair value for electric light per year? Surely these are facts that are demonstrable in this stage of the art, upon authoritative finding of an authoritative body.

Therefore the function of the Utilities Bureau in the first place is to get the facts, in the second place to spread the facts, and in the third place to use these facts to further efforts of the various municipalities, in fights that occur from time to time, either in securing necessary legislation, or in securing necessary regulation. In other words, the Utilities Bureau is a device, a modern device, of administration to meet a very practical situation. It is a device to use organized intelligence in the management of one of the most important phases of city affairs. As such I commend it to you. 